\title{
"Y se crían con grande vicio y abundancia": la actividad pecuaria en la provincia de Antioquia, siglo XVII
}

\author{
Yoer Javier Castaño Pareja \\ Universidad de Antioquia, Colombia \\ yjcastan@hotmail.com
}

\begin{abstract}
Resumen
En este artículo se pretende demostrar que no sólo la minería era importante en la provincia de Antioquia, sino que también era floreciente la actividad pecuaria, pues desde finales del siglo XVI, ya se criaba y cebaba ganado vacuno y porcino en los valles de Aburrá, Rionegro, Ebéjico, Urrao y Noque, para venderlo en los centros mineros del norte (Cáceres, Zaragoza, Los Remedios y, posteriormente, el valle de Los Osos). Por otra parte, los centros mineros de Cáceres y Zaragoza eran abastecidos por ganados que provenían de la gobernación de Popayán, especialmente de las ciudades de Buga y Cartago y del pueblo de Roldanillo. Por lo tanto, la actividad pecuaria era un ramo importante de la economía colonial antioqueña; aspecto que, infortunadamente, ha sido estudiado de forma muy somera.
\end{abstract}

Palabras clave: ganadería, comercio, minería, provincia de Antioquia, siglo XVII.

\begin{abstract}
The article seeks to demonstrate that not only mining was important in the province of Antioquia, but cattle raising was also flourishing. Bovine livestock and swine were raised and fed in the valleys of Aburrá, Rionegro, Ebéjico, Urrao, and Noque since the end of the 16th century, and they were taken to and sold in the mining centers of the north (Cáceres, Zaragoza, Los Remedios, and later on, the valley of Bears). On the other hand, the mining centers of Cáceres and Zaragoza were supplied with livestock that came from the government of Popayán, especially from the cities of Buga and Cartago, and from the town of Roldanillo. Therefore, cattle raising was an important part of the colonial economy of the province of Antioquia; aspect that, unfortunately, has been studied very superficially.
\end{abstract}

Key words: Cattle raising, trade, mining, Province of Antioquia, $17^{\text {th }}$ century. 


\section{Introducción}

Quien tuviere hatos de vacas, debe procurar las tierras viciosas y de grande yerba: porque los ganados mayores no se contentan con yerba menuda como las ovejas, y sobre todas las cosas quieren el pasto verde, más que heno ni paja ni otros pastos.

El término estancia es de origen americano. En tiempos de la Conquista ya se utilizaba en tierras antillanas, y designaba el punto en que al fin se asentaban el hombre y el rebaño nómadas. Usualmente se utilizaba con el sentido de detención, descanso y sedentarización. Y, en efecto, la petición de mercedes de tierra por parte de algunos individuos indicaba el deseo de echar raíces en tierras indianas. La Corona dio facultades para disponer de la tierra en Indias, ya por capitulación con los grandes inversionistas, ya por delegación en los jefes de hueste o conquistadores. Casi al terminar el periodo de la Conquista, la facultad de repartir tierras se depositó en los cabildos, siempre y cuando viniera la confirmación por parte de los gobernadores. De los adelantados pasó a los cabildos, y de ambos, a los gobernadores. Advenida la dinastía borbónica, el régimen de la tierra tuvo cambios considerables que están contenidos y pueden ser estudiados dentro de las reformas borbónicas.

En la Provincia de Antioquia, con base en documentos coloniales, la estancia era un lugar donde se alternaba lo agrícola con lo pecuario ("pan y caballería", "ganados de pan llevar"). Los gobernadores, como intermediarios entre la Corona y los súbditos, la otorgaban como recompensa a la labor desempeñada por algunos individuos en el proceso de conquista y pacificación de nuevos territorios. En este primitivo centro de producción de granos y de animales de consumo y de labor, el antiguo conquistador y guerrero pasaba a convertirse en colono, y encontraba cierto grado de reposo que las actividades bélicas no podían ofrecer.

Entre sus inciertos límites territoriales se presentaban relaciones de subordinación entre su dueño y los sujetos que ejercían el trabajo muscular y mecánico, muchos de los cuales eran indígenas al principio, pero paulatinamente fueron reemplazados por negros esclavos y por un poco de mano de obra concertada y asalariada de todos los colores. Indios, negros, mestizos y zambos trabajaban como arrieros, recueros, yegüerizos y porqueros; 
vaqueros, gañanes y queseros, y en otras poblaciones del Nuevo Reino, como cabreros y ovejeros ${ }^{1}$.

Desde 1564, con la merced de tierras otorgada a Juan Arias de Rubián por el gobernador de Popayán, Jerónimo de Silva, se comenzaron a dar estancias para la cría de ganado vacuno y caballar en las recónditas tierras de la provincia de Antioquia $^{2}$. En un principio, la mayor parte de ellas se ubicaban en las vegas del río Cauca, cerca de la villa de Antioquia y de la quebrada de Los Cedros. Otras más se otorgaron en los valles de Aburrá y Rionegro, y fueron dadas en su mayoría a hombres que habían prestado servicios a Robledo, Valdivia, Rodas y al capitán Gómez Hernández. Imposible fue determinar el número de cabezas que poseía cada individuo, pues desgraciadamente no se hallaron testamentos, avalúos e inventarios de bienes del siglo XVI, y por otra parte, las mercedes son muy parcas en cuanto a información pecuaria se refiere.

Sin embargo, gracias a unas pocas referencias que se hallaron, se pudo determinar que Antonio Machado tuvo hatos de vacas alrededor de las quebradas Sucia y Seca (AHA, $T$ 185, ff. 14v., 18r.); que Gaspar de Rodas otorgó para el sostenimiento de su hija María de Rodas y de su yerno Bartolomé de Alarcón, hacia 1591, aparte de tierras junto al río de Áburra, 400 reses vacunas y 40 yeguas (AHM 39, doc. 4, f. 5v.); que Juan Daza tenía caballos y terrenos con lamederos para el ganado, alrededor de la quebrada de Las Ollas (AHA, $T$ 155, doc. 4134, f. 17v.); que Diego de Maqueda, antes de 1569, poseía vacas y corral, aunque no se sabe dónde (AHA, $T$ 173, doc. 4499, f. 30v.), y que el capitán Juan de Zabala, en media legua, entre la quebrada Seca y el río de Áburra, tenía ganados de vacas y ovejas (AHA, $T$ 185, doc. 4665 , f. 36v.) ${ }^{3}$.

También llegaron a tener ganado en las riveras del río Cauca - puesto que les fueron dadas tierras de caballería, o aparecen mencionados como poseedores de estancias lindantes a las otorgadas en algunas mercedes- Gaspar de Rodas (quien tenía también estancias en los valles de Aburrá y Rionegro), Bartolomé Sánchez Torreblanca, Juan de Aldana, Francisco Alférez, Francisco Pérez Holguín, Francisco Martínez, Pedro Barbarán, Diego de Miranda, Fabiana

\footnotetext{
${ }^{1}$ Unas interesantes anotaciones generales sobre los oficios especializados en el ramo pecuario, ejercidos por indios y negros en Hispanoamérica, puede verse en Patiño (426-432, 508-511) y Colmenares (Popayán 185-193).

${ }^{2}$ La merced de tierra para ganado mayor se extendía desde "unas quebradas que entran en los Cedros, por el camino de Niquía arriba" (AGN, TA 4, f. 78r).

${ }^{3}$ No hay que confundir este río que queda en el valle de Ebéjico, con el río Aburrá, que se ubica en el valle donde se estableció la villa de Medellín.
} 


\section{FRONTERAS}

de la fistoria

Ordóñez, Francisco de Arce, Domingo Gómez, Francisco de Guzmán, Manuel López, Rodrigo de Santander, Juan de Bolívar, Damián de Goez, y Juan Burgueño. En el valle de Aburrá, Nicolás Blandón (también tuvo tierras de caballería en Rionegro), Bartolomé de Alarcón, Antonio Machado, Rodrigo García Hidalgo, Alonso de Rodas Carvajal y Juan Rodríguez Angulo.

Por lo tanto, en la provincia de Antioquia, hacia las cuatro últimas décadas del siglo XVI, existían estancias ocupadas en la cría de ganado vacuno y caballar, dispersas en las vegas del río Cauca y los valles de Aburrá y Rionegro. De muchas de ellas se llevaban reses y cerdos hacia los distritos mineros para apaciguar un tanto la alta demanda de elementos cárnicos. Decir que había mucho ganado sería una falacia, pues no habría sido necesaria la introducción de ganado desde Buga, Cartago, Roldanillo, Anserma y aun desde Pasto y Quito. También sería una argumentación sesgada afirmar que no había ganado en aquel período. Por eso, basta con decir que hacia finales del siglo XVI la cría de ganado iba cobrando un lento y paulatino impulso en la lejana provincia de Antioquia. Un desarrollo que sufrió crisis, depresiones y períodos de estancamiento durante las dos centurias siguientes.

El tamaño de las estancias era muy variable. Hubo algunas que llegaron a tener dos o tres leguas de longitud, según se expresa en las mercedes de tierras, y otras medían unas cuantas cuadras, conforme se dice en algunos documentos de compraventa. La mayor parte se componía de tierras de caballería, tierras de pan, trapiche, cañaduzal, platanar, sembrados de maíz y corral donde se hacía rodeo del ganado, y una casa de tapia, cubierta con techo de paja. Las estancias de mayores proporciones, donde el número de cabezas de ganado podía pasar de las 300 , no sólo tenían aquello, sino también indios encomendados, esclavos, casas de paja donde éstos habitaban, capillas, molinos, hornos, trapiches de mano y de caballo. Además, las principales estancias tenían bueyes que eran utilizados como animales de carga o de servicio en las labores agrícolas.

En general, las estancias antioqueñas poseían las siguientes características: una legua en cuadrado, con tierras de pan y caballería, trapiche de caballo, cañaduzal, platanar, casa de estantillería o de embarrado y cubiertas de paja, corrales de piedra o construidos con bambúceas, ranchería donde vivían los indios y dehesas donde pastaba el ganado. Por aquel entonces solía dárseles el nombre del dueño (Hato de Doña Juana) o se le llamaba por el nombre de la profesión que ejercía el propietario (Estancia del Contador, Hato del Alférez). Del mismo modo, era usual darle el nombre de una de las quebradas, amagamientos o de alguna peculiaridad geomorfológica que poseía la propiedad 
(Estancia de la Quebrada Seca). En casos excepcionales, el dueño podía darle el nombre del santo de su devoción (San Esteban, San Jacinto, Santa Ana).

Por ejemplo, el capitán Domingo Rodríguez (dueño de minas en el altiplano de Los Osos) poseía en 1685, en el sitio de Quirimará, una estancia de una legua "que corre desde el cañaveralejo, la loma de arriba hasta el cañaveralejo que es donde comienzan las tierras que fueron de Miguel Gómez de Ureña y una legua en cuadro vertiente al río de Cauca y por el otro lado las tierras de Machado con seis fanegadas de tierras de pan" (AHA, $M$ 291, doc. 5858, ff. 12r.-v.).

En ella tenía tierras de caballería, seis fanegadas de tierras de pan y una casa de 44 pies, construida con estantillería, cubierta de hojas de iraca y con puertas de cuero y una cocina de estantillo. En dichas tierras apacentaban 247reses, 10 yeguas, 5 caballos mansos y 8 mulas viejas y mozas, aparejadas.

El alférez real Pedro de Celada Vélez (dueño de mina en Las Ovejas) poseía en 1699 una estancia en el sitio de Nuestra Señora de la Concepción. Allí tenía una casa de tapia cubierta de paja, junto con una capilla de paja, un trapiche de caballo, un cañaduzal y un arado cercado. Varios negros esclavos se ocupaban en el trapiche y en labores agropecuarias. Además, cuidaban 377 reses, 4 yuntas de bueyes, 9 caballos de vaquería, 25 yeguas y 12 bestias mulares (AHJM, caja 180, doc. 3597).

El maestre de campo Antonio Zapata de Múnera tenía en 1672 una estancia en los aposentos de Guayabal (valle de Aburrá), donde había una casa de trapiche cercada de tapias, cubierta de paja y con un molino de tres mazas "corriente y moliente". También existían tierras para sembradura, en las que doce yuntas de bueyes con sus rejas removían la tierra. Además, existían varios corrales en las que el mayordomo Lucas de Herrera y los vaqueros Pedro de Herrera, Juan Antonio de Acevedo y José Suárez realizaban rodeos de ganado. Dicha estancia se componía de dos tipos de terrenos: el alto y el llano. En el terreno alto apacentaban 726 reses; en el llano, 535. Igualmente, había 73 yeguas y 24 mulas mansas (AHA, $M 229$, doc. 5267, ff. 54r.-55r.).

El agua tiene una extraordinaria significación en la crianza animal. No es una simple materia inerte o mero disolvente, sino un elemento estructural y activo. Un vacuno puede pasar semanas sin ingerir alimentos, pero la falta de agua, por pocos días, le causa la muerte. En Antioquia, la mayor parte de las estancias y sitios de cría ganadera se situaban donde existía abundante forraje, agua, numerosos lamederos y fuentes salitrosas. Las vegas de los ríos Cauca, Porce, 


\section{FRONTERAS}

de la historia

Rionegro y Penderisco fueron las favoritas, y mucho más aquellos parajes donde desembocaba un río tributario. Así, el agua, la sal y el pasto conformaban una tríada indispensable para entablar una estancia de ganado mayor. Si alguno de tales elementos faltaba, la actividad ganadera fracasaba. Las mismas condiciones debían poseer los lugares donde los vaqueros detenían temporalmente a sus ganados para que descansaran y recuperaran peso.

\section{Los núcleos ganaderos de la Provincia de Antioquia}

En las vegas del río Cauca, cerca de la villa de Santa Fe de Antioquia y de los pueblos de San Juan del Pie de la Cuesta y Sopetrán, se localizaba más antiguo núcleo destinado para la cría y levante de ganado mayor. Alrededor de las quebradas Seca, Sucia, Pocuná, Niverengo y Sisquiarco había unas cuantas estancias de ganado mayor. En estos lugares, explotados para la ganadería desde los últimos 30 años del siglo XVI, eran muy comunes los ojos de sal. Ganado vacuno y caballar era criado en la parte más baja y cálida, rica en hierbas naturales, como también en la franja montañosa, donde era necesario tumbar el monte para dejarlo apto para la actividad ganadera. En unas pocas décadas y como consecuencia del pisoteo del ganado, muchas colinas se vieron afectadas por la erosión y por los procesos acelerados de meteorización del suelo. Para acondicionar estas laderas, el ganadero recurría a quemar el bosque primario, y luego, cuando nacían los retoños de los pastos, introducía ganado mayor. Se dejaban en pie grandes árboles para que sirvieran de sesteadero a las bestias. A veces las tierras utilizadas llegaban a ser tan abruptas, que era frecuente que las vacas se despeñaran o rodaran. Por ejemplo, según cuenta Bernardo Jaramillo en un litigio que sostuvo con Gertrudis Delgado (dueña de reses y cerdos en el sitio de Pocuná), en pocas semanas un centenar de reses podía dejar yermas y estériles unas cuantas laderas:

[...] los dichos montes de pan no tienen entidad para sustentar por dos meses más de cien reses vacunas que tiene la susodicha [Gertrudis]... y que en los montes de sus tierras no puede entrar su ganado por que no tienen entrada y son laderas de montañas sin pasto, y por que así mismo se hallará que en las laderas de caballería en que le dio permiso el Capitán Estevan Jaramillo no puede pastar ganado por despeñadas y que son tan cortas que aunque pudiera pastar en ellas el dicho ganado las agostará en cuatro meses. (AHA, $T$ 158, doc. 4174, f. 13v.).

Los sitios aptos para la ganadería eran pocos y de cortas proporciones: Abejuco, Barahona, Goyás, Isima, Juan García, Pocuná, Quebrada Seca, Quirimará, Sisquiarco y Quebrada Sucia. Por eso, era común que la gente se enfrascara en litigios por la propiedad de las isletas del río Cauca, donde en tiempos de aguas 
bajas nacía un pasto rico en minerales muy apto para los ganados, y quedaban depositadas materias orgánicas que fecundaban el terreno y lo hacían muy atractivo para sembrar maíz y plátano. Llegaron a ser propietarios de ganado en aquel valle, y en distintos períodos, los Santander, Oliveras, Guzmán, Barrero, Daza, Díez de Balbín, Goez, Guetaria, Benítez, Burgueño del Castillo, Delgado Jurado, Flores, Jaramillo, López, Montoya, Ordóñez, Parias, Serna Palacio y Taborda.

El segundo núcleo donde se desarrolló la ganadería fue el valle de Aburrá. Sus suelos aluviales y sometidos a la acción periódica de las aguas por frecuentes desbordamientos del río del mismo nombre, hicieron posible que se convirtiera en un gran centro agrícola. El seco norte de la llanura y los pequeños valles transversales fueron preferidos para los hatos grandes, tales como los de Aná, Hatoviejo, La Tasajera, Hatogrande, El Hatillo, El Totumo, los Potreros de Barbosa y el sitio de La Eme, donde Cristóbal Valderueda tenía marranos, que luego vendía al capitán Diego Fernández Barbosa, para que abasteciera la carnicería de Los Remedios (AGN, $M$ 62, ff. 361-363). Hacia el sur (destinado a sementeras), existió ganado montaraz en el sitio de Güitaguy, y las tierras de la estancia de Guayabal. Del mismo modo, algunos indios y mestizos poseyeron vacunos en los terrenos del poblado de San Lorenzo ${ }^{4}$.

En Aburrá fueron notorios los hatos y las estancias de los Rodas, los Gómez de Salazar, los Toro Zapata, los Heredia, Alarcón, Suárez Barbosa, Beltrán de Caicedo, Bueso de la Rica, Mejía de Tovar, Castrillón, Velásquez de Obando, García de Ordás, García Hidalgo, González de Fresneda, Piedrahíta y Saavedra, Pimienta, Rondón y Zapata de Múnera; estancias en las que fácilmente el número de cabezas de ganado podía oscilar entre mil y cuatro mil animales, y en las que trabajaban muchas personas en las labores cotidianas, entre indios, mulatos y negros. En ese valle se criaba especialmente ganado mayor: reses, vacas, novillos, yeguas y mulas, que se llevaban a vender a Cáceres, Zaragoza, Los Remedios, Guamocó (de gentes mineras) y a la mismísima ciudad de Antioquia.

\footnotetext{
${ }^{4}$ Sobre el poblamiento y colonización del valle de Aburrá, véase Jaramillo.
} 
Mapa 1. Cría de ganados en el valle de Aburrá, siglos XVI y XVII

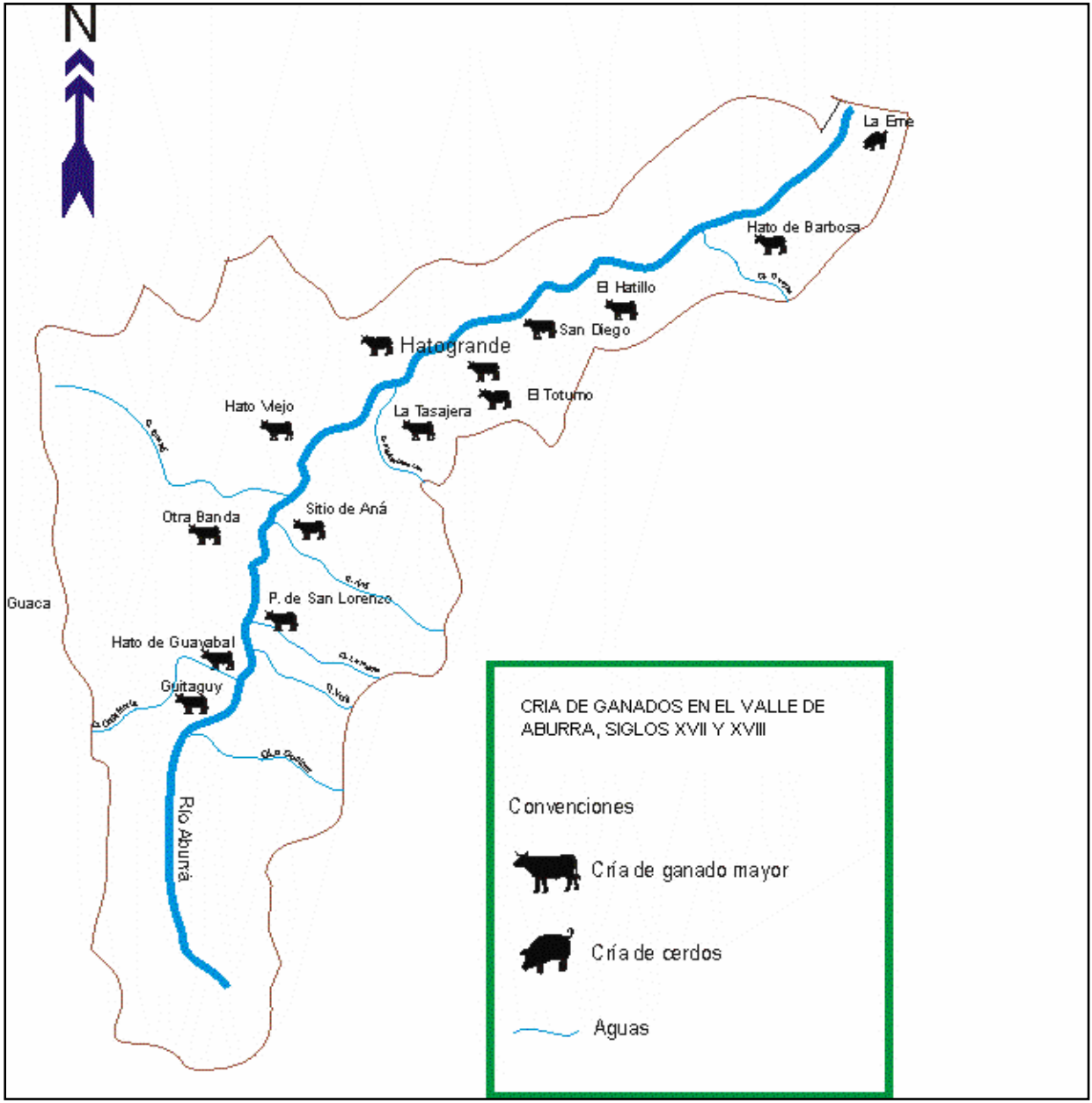

El tercer núcleo fue el valle de Rionegro, desde las minas aluviales de Guarne, Ovejas y Piedras Blancas hasta las estancias de Llanogrande, que pertenecía a la ciudad de Arma de la Gobernación de Popayán. Allí también fueron usuales las grandes propiedades donde no sólo se criaban millares de cabezas de ganado vacuno, sino también piaras de cerdos. Esta cría del cerdo era motivada por la explotación aurífera de las minas inmediatas de Los Remedios, y era facilitada por la geomorfología y las características climáticas imperantes, dado que el ambiente húmedo, frío y sombreado de las faldas de las montañas favorecía la cría de cerdos y permitía a estos animales obtener parte fundamental de su 
alimento hozando libremente en el bosque. Ganado vacuno y porcino hubo en los sitios de Guarne, Cantarranas, Matarredonda, La Mosca, San Nicolás el Magno de Rionegro y La Ceja (que era de Arma).

Numerosos vecinos de las ciudades reinosas de Tunja y de Santafé residían en aquel valle dedicándose a la cría, ceba y comercialización de puercos. En 1598, Andrés Garcés, portugués, criaba en el alto de Las Ovejas (Rionegro) cerdos pertenecientes a Juan Cajón de Porras y Pedro Jiménez Busto, ambos vecinos de Tunja. En el mismo año, Diego Álvarez y Juan Blandón y Quintana poseían mil cerdos criados en su estancia, y más de 700 traídos desde fuera (AGN, $M$ 62, ff. 361-370). Por su parte, en 1626, Antonio de Quiroga, quien criaba cerdos en el valle de Rionegro, envió a la ciudad de Zaragoza 603 marranos, divididos en cuatro partidas: una de 153, y las tres restantes, de 150 cada una. Al parecer, fueron enviados más puercos, pero muchos murieron "naturalmente", otros fueron devorados por fieras y no pocos se perdieron en el camino (AGN, JCA 13, ff. 1058r-1059v.).

Eran grandes propietarios en aquel valle los Blandón, Hidalgo y Rangel, Burgos Antolinez y Ruiz de la Parra. Todas estas familias, aunque tenían su vecindad en la ciudad de Arma, se movían constantemente entre los valles de Rionegro, Aburrá y Ebéjico, realizando negocios y transacciones.

El cuarto núcleo fue el valle de Urrao, con las fértiles vegas del río Penderisco, que tiene su origen en la cordillera occidental y en su parte baja es conocido como Murrí (afluente del río Atrato). Este valle alcanza los 1.885 metros sobre el nivel del mar y posee suelos aluviales pobremente drenados y con un nivel freático fluctuante. Algunos de éstos están enriquecidos con cenizas volcánicas.

Los Guzmán tenían salinas, tierras de pan llevar y de caballería desde Noque hasta Urrao, ya en el siglo XVII. También tuvo estancia de ganado vacuno por aquellos lares el alcalde ordinario de la ciudad de Antioquia y gobernador de la provincia entre 1658 y 1664, Juan Gómez de Salazar dueño, además, del Hato Grande, en el valle de Aburrá ${ }^{5}$. Sin embargo, el principal propietario de ganados en ese valle durante los años finales del siglo XVI y parte del XVII fue Damián de Silva, quien poseía un hato de vacas y varios indios titiribíes y negros que se ocupaban en la cría y comercialización de ganado, al igual que en la carga y

\footnotetext{
${ }^{5}$ La merced fue dada en 1622 por Francisco Berrío, gobernador de la provincia (AGN, TA 1, f. $644 v)$.
} 


\section{FRONTERAS}

de la historia

transporte de maíz y leña. Esos ganados, en su mayor parte cimarrones, pasaron a ser propiedad de Juan Jaramillo, su pariente, como pago de una deuda ${ }^{6}$.

Según la información hallada en los manuscritos, el ganado montaraz era bastante numeroso en Urrao. Allí se criaba y cebaba ganado con el objetivo de abastecer las minas del Chocó, en especial las de Nóvita, que fueron exploradas desde finales del siglo XVI, y explotadas desde mediados del XVII. También se criaba ganado para abastecer a los grupos militares que se adentraban para pacificar a los indios chocoes, carautas y guaracúes, considerados por los vecinos de la ciudad de Antioquia y de la villa de Santa Fe como "enemigos de la Corona de Castilla". Uno de los principales proveedores de carne para estas tropas fue el capitán Juan Jaramillo, quien para tales operaciones había sacrificado más de dos mil reses; además, había participado en las expediciones contra los indios carautas, llevando consigo 17 personas entre soldados y cargueros. Igualmente, había sido regidor, alcalde de la hermandad, alcalde ordinario y teniente de gobernador de Antioquia (AGN, M 37, ff. 16r. y v.).

\section{Salinas y ganados}

Varios son los aportes alimenticios que requerían los ganados. Además de pasto y agua era necesario proporcionarles ciertas cantidades de sal que los forrajes por sí solos no podían satisfacer. Los componentes minerales son imprescindibles, entre otras cosas, para un correcto desarrollo de las actividades vitales (crecimiento, locomoción, reproducción), para una buena formación ósea y para el correcto funcionamiento del sistema hormonal; su carencia puede ocasionar importantes trastornos patológicos.

La sal es indispensable para el ganado: sin ella mueren las crías, los ganados mamones enflaquecen y las vacas no dan leche. Sin la existencia de aquellos ojos de sal, de aquellos lamederos tan mencionados en los pleitos de tierras y sin la ayuda del hombre, el ganado no habría podido multiplicarse en ciertos espacios del orbe indiano y del territorio neogranadino ${ }^{7}$. El manejo de la sal le permite al hombre controlar los grandes hatos, así como curar y salar la carne. Sin estos procedimientos no se habría podido enviar tasajo y cecina a los lejanos distritos mineros de Cáceres, Zaragoza y Los Remedios. Las necesidades, además, se incrementaban en períodos y situaciones concretas (épocas de fuerte

\footnotetext{
${ }^{6}$ En 1626 el mencionado Pedro de Silva, declaró que sus padres habían reconocido una deuda con su pariente Juan Jaramillo, en forma de codicilo, la cual fue cancelada con la mitad del ganado cimarrón que había en el valle de Urrao (AHA, $T$ 141, doc. 3848, f. 2r).

${ }^{7}$ Sobre la importancia de la sal para los ganados, véase Roulin.
} 
calor, largas caminatas o trabajos intensos de los animales), por lo que las raciones de sal debían aumentarse.

Numerosas actividades ganaderas tenían a la sal como protagonista. En efecto, ésta se utilizaba para curar diversas enfermedades del ganado, como infecciones en los ojos, heridas en la piel y sarna. Además, se empleaba en la doma de novillos, dándoles sal y vino. La paja, el heno y la hierba eran rociadas con aguasal. También era importante el uso de la sal como conservante de las pieles de los animales que morían en los largos viajes hacia los distritos mineros y las carnicerías locales. Los dueños del ganado facilitaban a los vaqueros ciertas cantidades de sal a fin de que se la proporcionaran a las reses en tan extensas travesías, y pudiera conservarse la carne y las pieles de los animales muertos. Algunas veces los vaqueros utilizaban la sal de forma fraudulenta dándola a los ganados que iban a vender con el fin de avivarles la sed, por lo que bebían más agua y engordaban momentáneamente.

En la provincia de Antioquia fueron muy importantes, y explotadas desde tiempos precolombinos, las salinas de los municipios de Sopetrán y Guaca (hoy, Heliconia). Los antepasados sabían dónde hallar un salado con sólo madrugar, pues los animales del monte acudían allí a abrevar; también los distinguían por el color blancuzco en las vegas de algunas quebradas. Ellos diferenciaron entre la sal para consumo humano y aquella para los hatos y salazón de carnes. Esta última tendía a ser negruzca, aceitosa, poco yodada y de regular calidad. La sal de Sopetrán tenía estas características; mas no la de Guaca, que era blanca, apta para el consumo de las personas, y a la que se le atribuían virtudes medicinales.

Desde antiguo se usó que los dueños de una tierra que contuviera manantiales o quebradas salobres dieran permiso para que los dueños de hatos llevaran allí a sus animales. Cuando los dueños de los predios sintieron que soportaban una servidumbre de paso, lo impidieron mediante talanqueras. Por eso son abundantes en los archivos locales los conflictos entre agricultores y ganaderos, o entre hacendados y dueños de unas pocas reses por el acceso a los abrevaderos, pues los ojos salados eran considerados bienes realengos. Este tipo de conflictos fue notorio en el pueblo de Sopetrán, entre los indígenas y los blancos que, con sus esclavos, se internaban para beneficiar los ojos de aguasal.

Los dueños de hatos en los valles de Aburrá, Rionegro, Ebéjico y Urrao se proveían de sal laboreada en las famosas salinas de Guaca, la cual se trasportaba a Aburrá por un camino que traspasaba las tierras de María de Quesada. En un pleito entablado por Miguel Cipriano de Guzmán (hijo de Bernarda de Murga) 


\section{FRONTERAS}

de la historia

con varios individuos que pretendían la posesión de dicha salina después del fallecimiento de su dueño, el alférez Simón de Murga, se afirmó que allí compraban arrobas de sal los señores Mateo de Castrillón, el alférez Cristóbal Ruiz de la Parra, el capitán Juan Jaramillo, el alférez Pedro de la Serna Palacio y el capitán Pedro Martín de Mora, entre otros, quienes eran ricos mineros y ganaderos. La sal se acarreaba en mulas, desde Guaca hacia el valle de Aburrá, e indios y negros trabajaban en las labores que exigía el "misterio de la sal". Ella se sacaba en piedra, cuando era blanca o transparente, o se beneficiaba en eras o estanques, se cocinaba con leña e implicaba una inversión cuantiosa en pailas, ranchos, hombres, mulas, embalaje y transporte.

En efecto, Simón de Murga había llegado a tener una salina "copiosa, aviada y entablada" junto con 11 piezas de esclavos, 7 arrobas de cobre viejo y 18 libras de bronce. Luego de su muerte, pretendió aquella posesión el capitán Juan Jaramillo de Andrade, quien la compró en un remate, por 2.000 pesos. En un interrogatorio, el mencionado capitán afirmó que algunas de las piezas de esclavos que adquirió estaban lisiadas de la vista y de las piernas y que la salina se hallaba deteriorada, por lo cual había realizado una cuantiosa inversión (AGN, TEA 17, ff. 150r.-150v; años 1663 y 1664).

Ante la muerte social de Juan Jaramillo, pues éste resolvió pasar los últimos días de su vida en un convento de Honda (donde falleció en 1684), la salina pasó a ser administrada por Juan Gómez de Salazar, el mayor propietario de tierras y ganados en el valle de Aburrá. Poco tiempo después las salinas y las tierras fueron heredadas por Esteban y Alonso Jaramillo de Andrade, hijos de Juan Jaramillo. Éstos, a su vez, las vendieron el 26 de enero de 1690 a Juan Zapata y Múnera, también dueño de centenares de reses en el mencionado valle $^{8}$.

No sobra decir que la sal se intercambiaba por ganado y se vendía envuelta en pellejos de vaca o en cuero de carnero. En muchos casos servía de "moneda" para adquirir al menudeo huevos, plátanos, dulce, tabaco y otros productos para el sustento. Un intenso comercio de sal y ganado se efectuaba entre el oriente y el occidente del Nuevo Reino de Granada. A Popayán llegaba sal desde el alto Magdalena, y a Cartago, desde Santafé de Bogotá. En 1663, Gaspar de Orozco, vecino de San Sebastián de la Plata, se obligó a pagar a Diego del Campo Salazar (vecino de Popayán) 1.000 patacones de a 8 reales por cuenta de mil

\footnotetext{
${ }^{8}$ Sobre la historia de la explotación de la sal en Guaca, Sopetrán y otros lugares de la provincia de Antioquia, véase Ortiz.
} 
arrobas de sal. Para tal efecto se hipotecaron 60 bestias mulares aparejadas, y las cargas se entregaron en el tambo de Guanacas (ACC, $N P$ 13, ff. 21r.-21v.). Medio siglo antes, por su parte, Luis Rodríguez le había vendido al capitán Álvaro de Bedoya y a Tomás de Carmona (vecinos de Cartago), 30 machos y mulas de arria aparejadas, que fueron pagadas con 810 arrobas de sal, a razón de 27 arrobas por cada mula y macho (AHC, $J$ caja 1 , leg. 1 , f. 112r.).

\section{Medianos y pequeños propietarios}

En la provincia de Antioquia, durante el siglo XVII abundaban los pequeños propietarios de ganado, pues de la lectura de 185 testamentos (fechado el más antiguo en 1619 y el más reciente en 1699), el 79\% poseía entre una y cien cabezas de ganado (entre vacuno, caballar y algún porcino), frente al 18\% de los medianos propietarios (100-500 cabezas) y al 3\% de los grandes propietarios (1.000-5.000 cabezas).

En el valle de Ebéjico, especialmente en los pueblos de Sopetrán, San Jerónimo y los sitios de Sisquiarco, Quirimará, Isima, Abejuco y Tonusco Arriba, y las quebradas del Contador, Tafetanes, Los Cedros y Juan García, se concentraba la mayor parte de los pequeños propietarios, es decir, aquellas personas que tenían entre una y cien cabezas de ganado. Le seguía el valle de Aburrá, especialmente el sitio del pueblo de San Lorenzo. Era notoria la ausencia de pequeños propietarios en el valle de Rionegro. Por su parte, en el altiplano de Los Osos, la presencia de algunos pequeños propietarios comenzó a darse desde la década de los ochenta del siglo XVII. La mayor parte de medianos propietarios de ganado se congregaba, en orden de importancia, en los valles de Aburrá, Ebéjico y Rionegro.

Los propietarios que poseían entre uno y diez animales le daban especial consideración a su ganado caballar y mular, pues gracias al trabajo de éstos se proveían de un poco de oro en polvo para el sustento cotidiano. También le daban relevancia a la cría de cerdos, reses, novillos y vacas paridas y de leche, ya fuera para alimentarse con su carne o para proveerse de sebo, leche y quesos. Muchos de éstos tenían su ganado en las tierras de los ejidos (bienes propios de villas y ciudades), y unos cuantos llegaban a ser poseedores de almudes de tierras, con cañaduzal y un trapiche de molienda o de caballo. Escasos eran quienes podían dotar a sus hijas u ofrecer algunos bienes para la emancipación de los varones. 


\section{FRONTERAS}

de la historia

Vol. 12 / 2007

Distinto era el caso de los propietarios que tenían entre 20 y 100 cabezas, pues tendían a dotar a sus hijas con semovientes. Escasamente se otorgaban más de diez animales. De igual manera, los hijos varones, al llegar a la mayoría de edad o al momento de contraer matrimonio, recibían ganado o algunas tierras. No quedaban excluidos los hijos naturales. Muchas veces, el hecho de dotar a las hijas dejaba esquilmada la fortuna familiar; por eso, para impedir tal contratiempo se instauró como costumbre el que tíos, tías y abuelos aportaran algo para la dote. Vale la pena decir que algunos hijos derrochaban y arruinaban a sus padres al vender sin permiso sus ganados. Muchos de esos propietarios llegaban a poseer varias fanegas y cuadras de terreno, y no faltaba quien tuviera unos cuantos esclavos. Uno que otro tenía minas. Compartían con los grandes propietarios la preocupación por la cría de ganado caballar, sin restarle importancia a la posesión de reses, novillos, bueyes de arada y cerdos. La misma conducta tendían a adoptar los medianos propietarios, pero éstos, a diferencia de los grandes, y en homóloga situación con los pequeños, no se rehusaban a realizar tareas pecuarias cuando la necesidad lo ameritaba: no se sentían deshonrados por efectuar rodeos y por salir a desjarretar los animales montaraces. Por ejemplo, en 1615, en el sitio de la quebrada Honda, Alonso de Rodas 'el Mozo', descendiente del primer gobernador de la provincia, murió de un ataque al corazón cuando trataba de desjarretar un novillo cimarrón que se le había escapado del rodeo (AHA, $M$ 196, doc. 4820).

Casi la cuarta parte de los pequeños propietarios eran mujeres, muchas de ellas viudas. Otra porción (el 7\%) eran indios que poseían mulas para desempeñar su tarea de vaqueros, arrieros, transportadores de mercancías o peones de salinas. Ya en las primeras dos décadas del siglo XVII, cuando el sistema de la encomienda había entrado en crisis, algunos indios del valle de Aburrá tenían mulas, yeguas y vacas que a veces vendían o prestaban a los vecinos blancos.

Los indios y los negros expresaban afecto por sus animales, especialmente por vacas mansas de leche, mulas y yeguas, pues en sus testamentos los llamaban con nombres propios y describían sus características morfológicas. Ese mismo sentimiento hacia sus animales de labor era compartido por otros pequeños propietarios, poseedores de menos de diez animales, de los que una gran parte eran mestizos, algunos clérigos, forasteros, comerciantes, y unos pocos descendientes ilegítimos de familias poderosas. En ciertos casos, el animal al que se le daba nombre cambiaba de categoría, pues llegaba a ser considerado un amigo o un pariente que ayudaba a su poseedor a conseguir el sustento diario y aminoraba la rudeza del trabajo agrícola y minero; es decir, era el sustento de la casa, un apoyo en las tareas cotidianas y signo visible de estabilidad económica. 
Atentar contra la vida de este animal podía acarrear hondos sentimientos de culpa.

Entre los indios propietarios de ganado se encontraba Ana Anserma, natural del pueblo de San Lorenzo, quien poseía varias cabezas de ganado y realizaba sacas de novillos hacia Los Remedios (AHA, $M$ 197, doc. 4838). En el inventario de sus bienes, llevado a cabo el 14 de junio de 1627, consta que aquella tenía 26 vacas grandes de vientre, 13 terneronas de año y de año y medio e igual número de terneros. En los pantanos de la parte baja del pueblo tenía dos vacas mansas con sus crías, y en el hato del doctor Miguel de Heredia, otras dos vacas mansas con sus terneros. En total, poseía unos 60 vacunos. También era propietaria de yeguas, potros, mulas y cerdos. En su testamento le reclamó una yegua mansa al indio Miguel Ordóñez. Igualmente, le solicitó a los albaceas que le reclamaran al capitán Alonso de Rodas una mula ombligona negra, "la cual mula me la pidió el beneficiado Facundo Ramírez por orden del dicho capitán Alonso de Rodas cuando venía del Reino con enjalmas y lomillo y aunque yo la dicha Ana le pedido la mula al dicho capitán Alonso de Rodas no me la querido dar y pagar" (AHA, $M$ 197, doc. 4838, f. 126r.).

Dejó varios animales para diferentes efectos espirituales, la mayor parte de ellos dóciles. Para las misas de intercesión otorgó una mula bermeja, una vaca con su cría y una yegua. Lo mismo destinó para el cura que la enterrara. Para la cofradía de Nuestra Señora de la Candelaria, fundada en la iglesia de San Lorenzo, regaló una vaca. Finalmente, "para misal y hacer bien por su alma", donó al señor licenciado Miguel de la Chica una mula, una vaca, una yegua y un vale por diez pesos. Por los favores que recibió durante su enfermedad, regaló a Juan (criollo de Anserma) una yegua cerrera "con el lomo pintado" y un potro castaño "con una lista en la frente". Igualmente, no dejó de cumplir con sus obligaciones terrenales, pues para pagar el diezmo atrasado del año de 1622, dejó una yegua castaña "questa aquí abaxo en el chiquero de puercos".

Algo similar hizo con sus bienes el indio Benito Pirsa, quien poseía unas tierras en el llano de Miranda (terrenos del pueblo de Sopetrán) con un pedazo de platanar. Conforme al inventario de sus bienes, realizado en 1655, poseía tres caballos, uno de los cuales se llamaba "el Congo", y doce reses. Al doctrinero Antonio de Guzmán le cambió cuatro vacas (tres paridas y una horra) por varias misas. Úrsula, su esposa, al casarse con el indio recibió una ternerita, de la que habían procedido dos reses: 'La Atufada' y 'La Plata'. Al nacer su hijo Luisico, el indio le regaló una ternerita, hija de la vaca llamada 'La Escultora' (AHA, $M$ 274 , doc. 5712 , ff. 2 r.-2v.). 


\section{FRONTERAS}

de la fistoria

En el mismo año, el indio Francisco Prieto (vecino del pueblo de Sopetrán), repartió su ganado de la siguiente manera, mencionando en algunos casos el nombre del animal:

Ítem, mando una vaca para mi alma a que se digan de misas, ítem más una potranca cerrera para lo dicho, ítem dejo cinco vacas, cuatro paridas una horra $=$ ítem más cuatro terneros de dos años = ítem más dejo un caballo y tres yeguas y un potrico de año y medio que está sin hierro [...] ítem se le den dos vacas a mi hija Sebastiana, la vaca criolla y la hortelana = la orejona, la azabache se le dé a mi mujer = ítem la novillona que está en el llano de Miranda se le dé a mi hija = ítem la otra novillona se le dé a mi mujer = ítem la que queda horra se le dé a mi hijo Pedro = ítem una yegua y el caballo rucio se le dé a mi hija = ítem las dos yeguas rucias se le den a mi mujer $=$ ítem el potrico se le dé a mi hijo Mateo por su buen servicio. (AHA M 281, doc. 5748, ff. 3r.-4r.)

Numerosos indios forasteros frecuentaban los centros pecuarios y los distritos mineros de la provincia de Antioquia. Allí se desempeñaban como rescatantes. Algunos poseían arrias de mulas, destinadas para el transporte de personas, mercadurías y todo tipo de vituallas. En ocasiones fijaban su residencia en los pueblos, hasta que allí los sorprendía la muerte. Ejemplo de ello fueron los indios Andrés Chocontá y Marcos del Valle. Ambos habían sido dueños de mulas y residentes en el pueblo de San Jerónimo. El primero tenía allí cinco mulas, todas con sus enjalmas y aparejos. Estos bienes fueron pregonados en 1655. El macho 'Capitán' fue avaluado en 16 pesos de oro fino. Los demás animales (dos mulas y dos machos) a 8 pesos de oro por cabeza (AHA, M 320, doc. 6132; año 1655). Por su parte, de Marcos del Valle sólo se sabe que era natural del pueblo de Ambalema, y que en su testamento dejó seis bestias mulares de carga aparejadas (AHA, $M$ 307, doc. 6027, año 1681).

Escasos eran los negros que podían denominarse o considerarse pequeños propietarios, aunque algunos negros horros llegaron a tener cerdos y gallinas, y hasta reses y caballos. Por ejemplo, en 1657, el negro Andrés Jolofo tenía por bienes suyos 45 reses, 3 caballos mansos, 2 yeguas, 1 potro, 5 cerdos y 20 aves "chicas y grandes". A su hija Margarita, le dio cinco reses para el trabajo. Al parecer, su amo había sido el ya mencionado Juan Gómez de Salazar, miembro de una de las familias más acaudaladas de la provincia ${ }^{9}$. Asimismo, en el inventario de los bienes del negro horro Andrés Rodríguez consta que poseía

\footnotetext{
${ }^{9}$ Este testamento se halla inserto en la mortuoria del gobernador Juan Gómez de Salazar (AHA, $M$ 224, doc: 5214, f. 187r). Cabe agregar que este es el único testamento en el que se menciona, entre los bienes, a las aves de corral. El valor de éstas era ínfimo, y nadie se interesaba por nombrarlas. Véase, además Molina (31-36).
} 
dos yeguas de vientre, un caballo manso, una vaca con su cría y un macho manso mohíno.

De manera que una gran porción de individuos de la provincia y que integraban las castas más bajas de la sociedad colonial (entre mestizos, mulatos, indios y negros manumisos) derivaban su sustento cotidiano de la actividad pecuaria, ya fuera porque transportaban con sus mulas personas o abastos, porque comercializaban ganado menor y sus productos derivados, o porque trabajaban en las estancias como vaqueros, arrieros y matarifes. En sus testamentos era frecuente que regalaran novillos mamones a sus hijos pequeños, sobrinos, nietos y ahijados, con el fin de consolidar una fuente de recursos para la subsistencia de aquéllos cuando llegaran a su adultez; un corto capital que podía entregarse para la dote, en el caso de las mujeres, o para la emancipación, en caso de los varones. Asimismo, los más pudientes donaban ganado a las cofradías, lo ofrecían para misas de intercesión o con ellos pagaban los diezmos. Ese ganado, pues, era destinado para el bienestar del alma. Era el peculio que les aseguraba varias misas y oraciones, necesarias para apaciguar los sufrimientos del purgatorio. Con cabezas de ganado caballar, vacuno o porcino también se pagaban novenarios, se veneraba a los santos, se ofrecía limosna a las ánimas del purgatorio y se agasajaba a las iglesias. Por lo tanto, en esta economía agraria de ritmo muy lento, también los menos acaudalados subordinaban los valores terrenos a esperanzas escatológicas.

\section{Los grandes propietarios}

El ganado, como la tierra, cambiaba permanentemente de manos. De prolíficos suegros pasaba a modestos yernos mediante las dotes. De padres y abuelos, a hijos y nietos por razón de las sucesiones. De tíos a sobrinos, mediante donaciones y herencias. De padrinos y madrinas a sus ahijados, gracias a donaciones. De particulares a otros, por medio de compraventas, deudas, hipotecas y remates. Hubo riquezas ganaderas que se sostuvieron por generaciones, a pesar de tantos repartos. También hubo hatos que se convirtieron en matrices de otros. Una parte de los ganados que pacían en las sabanas de la provincia de Antioquia en el siglo XVII derivó de los ganados de los conquistadores Gaspar de Rodas, Bartolomé Sánchez Torreblanca, Juan Taborda, García Jaramillo de Andrade, Juan Daza, Rodrigo Hidalgo y Rangel, entre otros. Los descendientes de éstos casi siempre llegaron a ser grandes propietarios de ganado. Otros grandes propietarios no nacieron siendo tales, pues ya en su mayoría de edad, después de haber hecho una buena fortuna con el cateo y la explotación de yacimientos auríferos, decidieron invertir las 


\section{FRONTERAS}

de la historia

ganancias en tierras y ganados, bienes más estables y menos frágiles a los vaivenes del destino. Así llegaron a existir dos tipos de propietarios, aparte de los pequeños y los grandes: los viejos y los nuevos.

En la provincia de Antioquia, durante la segunda mitad del siglo XVI, varias mujeres descendientes de conquistadores enriquecieron aún más, con sus dotes, a sus maridos. Ellas eran las transmisoras de poder y riqueza. Mediante el sexo femenino se adquirían honores y preeminencias. Hombres ambiciosos veían en las hijas de hombres poderosos la entrada a círculos estrechos en los que se podía gozar de poder económico y político. Gracias a ellas se podía ingresar en las camarillas que monopolizaban las funciones del cabildo, el abasto de las carnicerías locales, la explotación aurífera de ciertos sectores y las relaciones mercantiles con otras gobernaciones. El matrimonio con una mujer poderosa permitía forjar alianzas entre familias, apaciguar roces, extinguir rivalidades e implementar uniones que incrementaban un poder que muchas veces traspasaba las fronteras de la provincia. Mediante sus dotes las mujeres cedían un estatus económico y político e impregnaban a sus maridos de una aureola muchas veces ausente antes del matrimonio, pues los convertían en encomenderos, mineros, ganaderos, miembros del cabildo, terratenientes y estancieros; en fin, en hombres modelo, que encarnaban el estereotipo preponderante en la mentalidad de las personas de aquel período (Gamboa).

Entre la mitad y una cuarta parte de una dote solía darse en ganado ${ }^{10}$. Miguel Velásquez de Obando, quien tenía su estancia en el valle de Aburrá, en el sitio de Aná, recibió como dote de su esposa, Ana de Castrillón, entre otras cosas, 160 novillos, diez vacas mansas, una yegua, un caballo y un negro esclavo. Al casarse, él introdujo de capital 400 reses mansas chicas y grandes, 10 bestias mulares y 35 yeguas y caballos (AHA, $M$ 311, doc. 6065, ff. 6r.-6v.). Por su parte, Diego Muñoz Bonilla, al contraer matrimonio con María de Alarcón, llevó por capital 500 reses vacunas, 9 mulas, poco más de 30 caballos y yeguas

${ }^{10}$ En la Provincia de Antioquia, las dotes tendían a ser irrisorias si se comparan con las payanesas. En mis pesquisas por los archivos no encontré que en Antioquia llegara a darse una dote tan cuantiosa como la de la payanesa Catalina de Zúñiga (hija legítima del capitán Francisco de Mosquera y Figueroa y de Leonor de Velasco, y esposa del capitán Lorenzo de Paz Maldonado), quien en 1593 recibió como dote la suma de 6.887 pesos y dos tomines de oro de veinte quilates, y entre cuyos bienes se contaron miles de yeguas, garañones, vacas, mulas, machos y bueyes de arada (AAP, leg. 3986, fotogramas 0095v.-0097v). Por otra parte, las ventas de ganado payanés eran dos o tres veces más numerosas que las antioqueñas. Era normal que en una de tales transacciones se vendieran entre 1.000 y 1.500 animales; mientras en Antioquia, era extraño cuando se pasaba de 500. A su vez, los propietarios de ganado vallecaucanos superaban con creces a los antioqueños, pues muchos llegaban a poseer más de 5.000 reses. 
y 150 puercos. Su esposa llevó como dote, entre otros bienes, un negro y 20 vacas. Éstos poseían su estancia en el sitio de Güitaguy, en el valle de Aburrá. A su vez, dotaron a sus hijas de la siguiente manera: a María, casada con Francisco Gil, le dieron 106 reses, 27 yeguas y caballos, 3 mulas cerreras y 200 pesos en novillos; a Sabina, casada con Francisco Giraldo, le otorgaron 100 reses, 8 bestias caballares cerreras y 3 mansas y una yunta de bueyes. Por otro lado, a sus hijos José y Fabián los emanciparon otorgándoles ganado vacuno. Así, al primero le dieron 100 reses y 20 bestias caballares; y al segundo, 140 reses, 30 yeguas y 6 caballos mansos.

Una característica permanente entre los grandes propietarios de ganado era su intervención en las explotaciones auríferas y su participación en los cargos burocráticos del cabildo, la posesión de encomiendas, el monopolio de las carnicerías locales y su preocupación por la cría de mulas, machos, burros garañones, bueyes de arada, yeguas y caballos, pues cuanto más ganado caballar se poseyera, mayor era el prestigio y el abolengo, y la exaltación de su vida hidalga.

Muchos de ellos no residían en las estancias, sino en sus moradas de la ciudad; por lo que eran propietarios ausentistas, que tenían para su servicio a indígenas y negros esclavos, y a un amplio grupo de gente asalariada. Integraban camarillas en el cabildo, poseían una intrincada red de relaciones de parentesco y parentela con otras familias poderosas (ya fueran nativas o foráneas) y llegaban a tener propiedades con una extensión de una legua "en cuadro" o más, gracias a mercedes, herencias o procesos de compraventa. Casi en su totalidad, los más grandes hatos ganaderos (entre 500 y 4.000 cabezas) se concentraban en el norte del valle de Aburrá, en los sitios de Aná, Hato Viejo, La Tasajera, Hatogrande, el Totumo, el Hatillo y los potreros de Barbosa; y hacia el sur del Valle, en los sitios de Güitaguy y Guayabal.

Sin lugar a dudas, el mayor propietario de ganado vacuno y caballar en la provincia de Antioquia, durante el siglo XVII, fue el ya aludido Juan Gómez de Salazar, quien llegó a poseer 4.101 cabezas de ganado, entre vacuno y caballar, repartidas entre su estancia de San Esteban y los sitios del Hatillo y El Arado, en el valle de Aburrá (AHA, $M$ 224, doc. 5214). Su fortuna ganadera sólo llegó a compararse con la de Pedro Martín de Mora, gran propietario del siglo XVI, quien alcanzó a tener poco más de 3.000 reses, algunas de las cuales fueron compradas a Alonso de Rodas. Otro propietario fue Juan de Piedrahíta y Saavedra, quien llegó a poseer más de 1.600 animales. De este modo, en su estancia del valle de Aburrá, tenía 255 yeguas y caballos mansos, 11 mamones, 


\section{FRONTERAS}

de la historia

640 reses cerreras, 681 reses mansas, 9 yuntas y media de bueyes de arar y 2 yuntas de bueyes de tiro (AHA, $M$ 274, doc. 5703, ff. 11r.-18r.). Otros dueños de cabezas de ganado fueron: Antonio Zapata de Múnera (1.383 animales), Francisco Beltrán de Caicedo (1.050), el viejo Cristóbal Ruiz de la Parra $(700)^{11}$, Mateo de Castrillón (700), Roque González Fresneda (658), Rodrigo García Hidalgo (640), Alonso Velásquez de Obando (544), el alférez real Pedro de Celada Vélez (431) y Esteban Jaramillo de Andrade (425).

Por lo tanto, como puede apreciarse, muchos habitantes de la provincia de Antioquia amasaron fortunas personales con la cría de ganado vacuno, su distribución hacia los distritos mineros y el abasto de las carnicerías locales. Algunos de estos individuos compartieron la actividad pecuaria con la extracción aurífera, la comercialización de esclavos y el ejercicio político en los ayuntamientos. No pocos llegaron a ostentar el cargo político más importante en la provincia: el de gobernador.

\section{Distribución y comercio de ganado}

Desde mediados del siglo XVI, las ciudades de Buga y Cartago estuvieron ligadas a la provincia de Antioquia por una intrincada red de relaciones comerciales y de vínculos parentales. En Buga, en sus amplias y ricas dehesas bañadas por los ríos Guadalajara, Amaime y Fraile, y que se extendían desde el piedemonte de la cordillera central hasta el meándrico río Cauca, pastaban miles de reses que sus dueños criaban y cebaban con el fin de venderlas para el abasto de las cuadrillas de los centros mineros del norte de la vecina provincia de Antioquia (Cáceres, Zaragoza, Guamocó) y de los valles de Aburrá y Rionegro

\footnotetext{
${ }^{11}$ Tenía hato de ganado en la otra banda del Rionegro, en el sitio de Cantarranas (dehesa y tierras que medían un poco más de una legua, y donde existían corrales y ranchos de estantillos y paja) y algunos equinos en el Potrero de La Ceja. Conforme a lo que se dice en el inventario de sus bienes, efectuado en 1669, tenía en el hato de la otra banda del Rionegro 500 reses de ganado vacuno de un año para arriba, 55 cabezas de dicho ganado de un año para abajo mamón, 114 cabezas de yeguas. Del mismo modo, en el potrero de La Ceja había 10 potros y 20 caballos mansos. En el momento de este inventario, tres negros laboraban en el hato. Tenía ranchería y queseras junto a la quebrada de Espinosa (AHA, M 323, doc 6173). En 1656 compró a Miguel Velásquez un hato ganadero, compuesto de vacas, yeguas, caballos y ganado de cerda, y dos estancias (AHA, $M$ 162, doc. 4246, f. 30v). La familia de La Parra llegó a ser poseedora de las tierras que en aquel altiplano tuvieron Rodrigo Hidalgo y Rangel, Nicolás Blandón y Gaspar de Rodas (AHA, $M$ 162, doc. 4246).
} 
(un poco más al sur). También cebaban novillos para ser comercializados en el Chocó, Popayán, Pasto, Ibarra, Riobamba y Quito ${ }^{12}$.

Los ganados también eran abundantes en Cali y sus términos, y se enviaban a vender hacia los confines de Antioquia y de la actual república del Ecuador. Así, Cristóbal Quintero Príncipe se comprometió a entregar con un año de plazo, en 1619, en el valle de Aburrá, 600 vacas de dos, dos y medio y tres años; 600 novillos de tres, cuatro y cinco años; 20 caballos y dos bueyes, a 2 pesos 6 reales por cabeza, al sargento mayor Fernando Caicedo, santafereño, vecino de Los Remedios. Por otro lado, Rodrigo Albarracín Bustillo hizo compañía en 1624 con un vecino de Anserma, Gonzalo Gómez de Herrera, para llevar centenares de marranos desde Cali hasta Cáceres, Zaragoza y Los Remedios, muchos de los cuales fueron adquiridos en el trayecto, especialmente en Roldanillo y Riofrío. Y cabe mencionar que casi 30 años antes de este negocio habían hecho compañía Juan Galindo y Pedro de Zárate para vender 1.122 cerdos en la ya mencionada ciudad de Zaragoza (Arboleda 168-69) ${ }^{13}$.

Los indios gorrones del pueblo de Roldanillo también transportaban ganado hacia Los Remedios, Zaragoza y las sabanas de Rionegro y Aburrá, en un viaje que podía durar un poco más de dos meses. Por cada mil reses transportadas eran necesarias 20 personas, 50 o 60 caballos, una docena de mulas y una considerable cantidad de frenos y avios. De modo que un novillo que valía en las estancias vallecaucanas 1,5 pesos, llegaba a costar en los distritos mineros cuatro veces ese valor ${ }^{14}$.

Entre los límites de la provincia de Antioquia también era usual la compra y la venta de ganado, al igual que la de tasajo, cecina, sebo, jabón y cueros. Este aspecto es fácil de vislumbrar en los juicios de sucesión, en los que aparece información sobre las deudas que los testadores habían adquirido con tratantes y mercaderes. En este mismo tipo documental también es posible observar la relación entre criadores de ganado y mineros. Cabe aclarar que muchas de estas personas ejercían ambas funciones. Otra fuente valiosa para reconstruir el comercio ganadero provincial de aquel entonces resultan ser los libros de sisas,

\footnotetext{
${ }^{12}$ Para Antonio Vásquez de Espinosa, en su Compendio y descripción de las Indias Occidentales, "la ciudad de Buga dista 12 leguas de Cali al Norte, es de temple de primavera, lugar de mucho regalo, y frutas, tiene en su distrito muchas estancias con grandes crías de ganado mayor".

13 Sobre este comercio interprovicial ganadero, también pueden consultarse, Castaño y Colmenares (Cali y Popayán).

${ }^{14}$ ACC, serie Col. CI-19h, doc. 1621. f. 23v. Más información sobre este Hato Real se halla en la serie Col. CI. 13rc., doc. 318 y en la serie Col. CI. 20cr., doc. 1160.
} 


\section{FRONTERAS}

de la fistoria

un impuesto colonial, reminiscencia tributaria medieval, que consistía en un tanto por ciento que en beneficio del erario de alguna ciudad o villa se sustraía por la introducción de mercaderías. Sisas y alcabalas se cobraban por la introducción de cargas de miel y vino; ropa de Quito, del Reino y de Castilla; hierros y novillos; cargas de sal, azúcar y harina ${ }^{15}$.

Según se advierte en los mencionados libros de sisas y en otros tipos documentales, se llevaban piaras desde el valle de Rionegro y las estancias de Sonsón (en la vega de Supía), así como arrias desde las sabanas de Cancán, hasta Los Remedios; hatos de vacunos desde los valles de Aburrá y Rionegro, hasta las estancias de Guarne y las minas de Zaragoza, Cáceres, Guamocó, y a finales del siglo XVII, al valle de Los Osos; puercos y gallinas del pueblo de los indios pencos y carautas y mulas del pueblo de Sopetrán, hacia los reales de minas del cerro de Buriticá; ganados del Hatillo, Hatogrande y El Totumo (en el norte del valle de Aburrá) a los minerales de Los Osos, la quebrada del Espinal y el páramo de Cuerquia. En fin, la provincia de Antioquia poseía una intrincada red de relaciones comerciales entre sus centros ganaderos y sus distritos mineros, lo que nos demuestra que desde finales del siglo XVI ya se había establecido en ella un mercado ganadero con sus áreas de producción, de recolección y de consumo del producto $\mathrm{y}$, a la par, se llevaban a cabo contrataciones libres que se verificaban entre productores (mayoristas y minoristas) y consumidores.

La fortaleza de los vínculos comerciales no siempre fue igual, pues cuando cierto distrito minero entraba en colapso, los ganaderos disminuían el número de sus envíos y se concentraban en abastecer otros reales de minas más prósperos, pues allí encontraban en abundancia el oro en polvo y no tenían que fiar sus animales, con el riesgo que ello implicaba; situación que seguramente se

\footnotetext{
${ }^{15}$ En 1640, los miembros del cabildo de la ciudad de Antioquia — Juan Mejía de Tovar y el capitán Juan Lorenzo de la Rocha (alcaldes ordinarios), Juan García Ordás y Figueroa (alférez mayor), Diego Beltrán del Castillo (provincial de la santa hermandad), Fernando de Toro Zapata (alguacil mayor), Martín Delgado Jurado y el capitán Juan Jaramillo (regidores), Mateo de Castrillón (depositario general), Domingo de Elorza (tesorero y contador de la real caja) y el capitán Fernando de Montoya (procurador general) - establecieron que la sisa se cobrara en los siguientes géneros: "en cada fardo de ropa de castilla dos tomines de oro en polvo $=$ de hierro, acero y otros géneros de cada quintal un tomín; de cada botija de vino un tomín = de cada costal de harina un tomín; de cada negro bozal un peso= de cada anega de maíz que viniere de acarreto un tomín = de cada fardo de ropa de quito un tomín= y otro en los del reino; y en cada cabeza de ganado mayor y de cerda un tomín; de cada mula que se vendiere un tomín = de cada petaca de tabaco, conserva, bizcocho, azúcar y otros géneros de cada tercio otro tomín" (AGN, IV 19, ff. 964-972).
} 
dio entre 1610 y 1650 , la peor etapa de la crisis minera para los tradicionales centros auríferos de Cáceres, Zaragoza y Los Remedios ${ }^{16}$.

A finales del siglo XVII, algunos mineros empezaron a criar sus propios cerdos, gallinas y reses alrededor de sus minas para reducir los costos de producción en sus actividades extractivas y limitar las nefastas consecuencias de la crisis, ya que a juzgar por lo que se dice en las mercedes y concesiones de aquel entonces, se debía destinar una parte del terreno para pastos y abrevaderos. Igualmente, en ese predio se destinaba una porción para la siembra de maíz, con lo cual se alimentaba a los cerdos y a los esclavos. Incluso, algunos negros eran destinados a criar cerdos y a la siembra y cosecha de granos. Estas formas de autoabastecimiento posiblemente menguaron la acción de los señores del ganado y la dependencia que en tiempos pasados habían tenido los distritos mineros de los centros ganaderos. Puede pensarse que la crisis obligó a que se empezara a alternar la minería con la ganadería y la agricultura, lo cual aminoraba los gastos del minero, le permitía invertir en otras ramas económicas más estables y diversificar sus fuentes de ingreso.

Preponderaba el comercio entre particulares. En la iniciativa individual se sustentaba este mercado provincial usualmente controlado por los miembros de unas pocas familias. Muchas veces la gente de bajos recursos se asociaba para satisfacer la demanda de los consumidores en cierto sector de la provincia, como lo hacían los indios o algunos gremios de muleros, muchos de los cuales habitaban en los pueblos de San Jerónimo y Sopetrán, y en las sabanas de Cancán.

Cerdos en pie, tasajos, lomos, costillas, longanizas y manteca también eran requeridos constantemente por los señores de cuadrilla. En Guamocó, Cáceres, Zaragoza y Los Remedios esta demanda era satisfecha por criadores de Rionegro, Aburrá, algunos reinosos, unos pocos payaneses y una fracción de comerciantes de algunas poblaciones del Bajo Magdalena (Tamalameque, Simití y Ocaña); en el valle de Los Osos, por gente de Sopetrán y Aburrá. Por ejemplo, en 1655, Gaspar Fernández (residente en Guamocó) le pagó a Bartolomé Arias (residente en Rionegro), 235 pesos por la compra de un atajo de puercos. Estos animales fueron conducidos desde Rionegro hasta Guamocó

\footnotetext{
${ }^{16}$ Los comienzos del siglo XVII marcan el preludio de una crisis que se prolonga hasta lo que parece el fin de la economía del oro en el Nuevo Reino de Granada, en 1660. Gran parte del oro extraído durante este lapso eludía las imposiciones fiscales, el pago de los quintos y la acuñación en las cajas reales. Así que parte de esta crisis puede atribuirse a la influencia perniciosa del contrabando y del oro en polvo.
} 


\section{FRONTERAS}

de la historia

por José de Bedoya, a quien Gaspar Fernández pagó 2 pesos por realizar el viaje. También pagó 58 pesos a Cristóbal de Serpa por la venta de una pequeña partida de cerdos (AHA, $M$ 215, doc. 5093). Doce años más tarde, Jacinto Fernández de Ayala, vecino de la ciudad de San Antonio de Toro, cobró en Guamocó 25 pesos por la venta de diez arrobas de carne, 10,5 pesos por dos tocinos, 34 tomines por 17 barras de longaniza, 2 pesos por dos lomos y dos costillas de puerco, y 10 tomines por media botijuela de manteca (AHA, M 321, doc. 6146).

La dieta de carne de cerdo de los mineros alentó una incipiente manufactura casera de cecinería, salazón y embutidos. Para sacar la manteca del cerdo bastaba con fundir las empellas en una paila y a una temperatura apropiada para evitar que se ennegreciera y adquiriera mal sabor. Esta manteca era envasada en la vejiga del animal. Se consideraba que la grasa de cerdo poseía propiedades curativas. Por ello, era utilizada para curar las heridas de los negros de mina. Alonso de Herrera aconsejaba en su tratado de agricultura: "es muy bueno que el lugar donde ha dado la landre, o seca, le unten mucho con manteca de puercos, y todo aquel miembro que está emponçoñado, han de untar con la misma manteca porque con esta untura se esparze la ponzoña, y no tiene tanta fuerza, y arropen la unción” (lib. V, cap. XL).

Del mismo modo, el tocino gordo era útil para las quemaduras, las hinchazones, los apostemas y para matar piojos y liendres. Por otro lado, los intestinos del cerdo se empleaban (y se emplean hoy) como envolturas para la fabricación de embutidos. Con éstos se hacían chorizos, longanizas y morcillas. Y en cuanto a las reses, de su cuero se elaboraban petaquillos, puertas, camas y zurrones en los que se transportaba la sal y el cacao. Con las patas y los cuernos se hacía jabón. Con la gordana y el sebo se preparaban velas, con las cuales se alumbraban los hogares, los íconos religiosos de los templos y las minas de veta.

Según se observa en varias mortuorias, los mineros también compraban al menudeo vacunos, mulas, aves y huevos, así como productos derivados de la carne, el sebo y la leche; todo lo cual era ofrecido por medianos y pequeños propietarios, o revendido por rescatantes. Así, el capitán Alonso Ruiz de Rivera, por medio de sus apoderados y de sus criados Lázaro Martín Gaviria, Guanteros, 'el Capuche' y el negro Miguel, le ofrecía al alférez Juan García de Ordás, para el abasto de su mina de San Pedro, arrobas de tasajo, quesos, jabón, vacas para ración y novillos para extraer gordana (AHA, M 223, doc. 5196). Por otro lado, en 1636, Francisco de Trejo enviaba fletes de mulas cargadas de 
tasajos, sebo, gordana, gallinas y quesos, desde su estancia ubicada en las vegas del río Cauca, hasta las minas de Los Remedios y las sabanas de Cancán. Una cargazón de cuatro mulas con aquellos productos fue vendida a Martín Salguero; dos arrobas de tasajos, al portugués Fernán González; una arroba de lo anterior, a Ana de Mina, mujer de Francisco Ruiz Zurita, y Antonio Graciano recibió cuatro mulas cargadas con 30 quesos, 16 arrobas de carne y 30 gallinas, todo lo cual tuvo un costo de 100 pesos de oro de Los Remedios. Juan Pérez de Medina le debía cinco cargas de sebo, carne y gordana. También un indio llamado Andrés, de la encomienda de Juan Jaramillo, le adeudaba una arroba de tasajo, que se había comprometido a pagar con dos cuartillos de miel (NUSA, $L$ ff. 1r.-6v.).

Matías Sánchez tenía ganado vacuno y equino en el sitio de Goyás. Según expresó en su testamento, efectuado en 1661, su hijo llevó a vender a Cáceres una partida de puercos y un atajo de ocho novillos (AHA, $M$ 293, doc. 5886, f. 18r). En el mismo año testó María de Vargas, quien tenía tierras y ganado en La Sucia. Esta declaró que su hijo Bartolomé Sánchez había llevado a Cáceres seis reses vacunas que ella le había entregado (AHA, $M$ 308, doc. 6038). Por su parte, en 1685, el capitán Pedro Gutiérrez Colmenero, quien tenía mina en Santa Rosa, declaró en su testamento que debía doce pesos en gallinas y capones, y cuatro pesos en huevos (AHA, $M$ 206, doc. 4982). Finalmente, Francisco Gil Bermúdez, declaró un año después que había entregado 30 reses como pago de una deuda al cura de Medellín Lorenzo de Castrillón (AHJM, caja 179, doc. 3594, f. 3r.).

Negros e indios tenían relaciones de intercambio y de compraventa con blancos y mestizos. Así, un indio llamado Guaba había vendido al ya mencionado Matías Sánchez, poco antes de que se casara, una res, y Juan José Rondón negoció una yegua con uno de sus negros, llamado Gregorio. En situaciones de esclavitud algunos negros les compraban ganado a sus propios amos, con el fin de sacar multiplico y crear un corto peculio, que podía destinarse después para comprar la libertad. Y pardos adinerados, que ejercían la minería, enviaban a comprar ganado a Rionegro. Tal fue el caso de Juan de Mora, quien en 1698, envió a Marcos Cardona a ese valle para adquirir novillos (AGN, C 17, f. 44r.).

\section{Los caminos del abasto}

En el valle de Aburrá, sitio de paso y lugar por donde transitaba una numerosa población flotante, existían caminos que lo comunicaban con el valle de Rionegro, al oriente; uno de ellos salía desde el sitio de Aná, y el otro iba por La 


\section{FRONTERAS}

de la historia

Tasajera. Se comunicaba también con la ciudad de Antioquia, al occidente: por un camino se atravesaba el sitio de Urquitá (por la culata de San Cristóbal), por otro se surcaba la loma de Angulo y uno más se metía por los aposentos de Niquía, subía la cuesta, atravesaba el valle de Ovejas y descendía a la ciudad de Antioquia. Este último camino también comunicaba el altiplano de Los Osos con el valle de Aburrá. Además, estos dos últimos lugares se comunicaban por otro camino que salía desde las tierras del Totumo (en el norte del valle de Aburrá) e iba a dar a las dehesas de la quebrada del Espinal (hoy, Don Matías).

Por otra parte, los vecinos de la ciudad de Antioquia llevaban novillos hacia el altiplano de Los Osos, al oriente, para lo cual se utilizaban los caminos que desde el pueblo de Sopetrán ascendían las lomas de El Cofre y Monte Grande y se introducían en los minerales de Riochico, Petacas, Riogrande y El Espinal. Así mismo, en dirección sur, por la loma de Quirimará y el sitio del Cañaveralejo, iba un camino hacia Caramanta, Arma y Cartago. Al decir de Francisco Taborda en 1617, "el que siempre se ha llamado Cañaveralejo y ha servido de dormida y rancheadero cuando se andaba el camino por la dicha loma para Caramanta y Arma y las demás ciudades de la gobernación" (AHA, $T$ 160, doc. 4216, f. 60v.).

Hacia el norte se dirigía un camino que comunicaba a Antioquia con Cáceres, y existía otro, al noroeste, denominado "de Antioquia la Vieja que llaman Cañasgordas" por el que se iba hacia Cartagena. Al occidente había un camino desde Noque al valle de Urrao; a su vez, desde Urrao se iba al Chocó por los ríos Murrí y Bebará.

Desde el valle de Aburrá, siguiendo el curso del río Porce y pasando por la sabanas de Cancán, iba un camino hacia Santafé y Cartagena, que aunque trajinado por gente de Medellín y Santafé (Juan y Pedro Martín de Mora, el maestro Tomás Francisco de Arnedo, el capitán Juan Jaramillo, Roque de la Torre Velasco y el santafereño Bartolomé Piñeros, entre muchos otros) era peligroso para los arrieros, las mulas y las mercadurías, pues no estaba reparado ni aliñado (AHA, $T$ 162, doc. 4245, ff. 37r.-v.).

El camino que se utilizaba para traer animales desde la Gobernación de Popayán comunicaba los sitios de La Vega de Supía, Las Tapias, Los Órganos y Pueblo Blanco (hoy, La Pintada), de donde partían el de Santa Bárbara y el de Sinifaná, para llegar al valle de Aburrá. También se llevaban ganados desde las mencionadas ciudades de Buga y Cartago hacia Los Remedios, pasando directamente por el valle de Rionegro. Para este efecto, debían superarse los 
pasos de Bufú y Moná, sobre el río Cauca (jurisdicción de la ciudad de Arma) y ascender por Sabaletas o por Sonsón. Los indios vaqueros de Roldanillo utilizaban una u otra vía; pero antes debía cruzarse el paso de Bedoya, o en su defecto el de Irra, lo cual les posibilitaba trasladarse de una a otra banda del río Cauca.

Fuera de los caminos mencionados, también existían sitios de paso y permanencia temporal para vaqueros y ganados. De este modo, hacia el norte y el nordeste de la provincia de Antioquia se encontraban dos lugares destinados a la instalación temporal de los ganados: el valle de San Andrés y las sabanas de Cancán, respectivamente. En el primer sitio, en la jurisdicción de Cáceres, inmediato al río Cauca, paraban a descansar los ganados que desde Antioquia se enviaban a esa ciudad minera; al igual que los viajeros y las acémilas que se dirigían hacia Cartagena y Mompox, o viceversa. En el segundo lugar descansaban los ganados que iban de Antioquia y del valle de Aburrá a Zaragoza, Los Remedios y Puerto de Nare (que no pertenecía a la provincia de Antioquia, sino a la jurisdicción de Los Remedios). También llegaron a criarse mulas que eran utilizadas para llevar fletes a Puerto de Nare, sobre el río Magdalena. La constante demanda de animales de trabajo en las minas de Los Remedios, junto con el continuo trajín de individuos y mercadurías hacia los puertos fluviales del río Magdalena, hicieron posible la aparición de este importante centro de cría mular, pues hacia el año de 1601 se contabilizaron allí casi 400 mulas y muletos. Era, además, un lugar de referencia donde los viajeros que venían de Antioquia o aquellos que retornaban de Santafé y Honda adquirían la mano de obra y los animales de transporte que les permitían llegar a sus lugares de destino (AGN, $J C$ 18, ff. 768v.-769r.).

Por su parte, los vaqueros y ganados que provenían de Buga y Cartago y que se dirigían a los centros mineros del norte de Antioquia se detenían, primero, en el lugar denominado La Paila (entre los actuales municipios vallecaucanos de Bugalagrande y Zarzal) no se sabe por cuanto tiempo, y posiblemente realizaban una jornada intermedia en Cartago o en Quindío. Después se realizaba otra parada en el sitio llamado Las Tapias. Luego se pasaba a la fértil Vega de Supía, donde poseían sus estancias ganaderas y sus minas algunos vecinos de Anserma. Posteriormente, se vadeaba por uno de los citados pasos el río Cauca, y se descansaba en el sitio Pueblo Blanco (hoy, La Pintada) o en el paraje Los Órganos. Después de esto se ascendía la empinada cuesta que llevaba hacia la divisoria de aguas de Santa Bárbara o se subía por el camino de Sinifaná, para descender luego al valle de Aburrá. 


\section{FRONTERAS}

de la fistoria

En el sitio de la Vega de Supía, perteneciente a la Gobernación de Popayán y la ciudad de Anserma, descansaban y engordaban, por un corto período, las reses y novillos que desde Buga y Cartago se llevaban para los centros mineros de Cáceres, Zaragoza y Los Remedios. Como tales ganados debían pasar por jurisdicción de la ciudad de Anserma, las autoridades de ella les cobraban impuestos a los vaqueros que se alojaban allí temporalmente. Este gravamen, que hasta 1696 consistía en el pago de 70 pesos de oro corriente anuales, aumentó a partir del año siguiente; fuera de ello, los alcaldes ordinarios de tal ciudad exigieron la cancelación de diez reses por cada cien animales, 1 real por cada cabeza de ganado y el pago de la alcabala. En 1701, esos numerosos impuestos que los alcaldes ordinarios de Anserma exigían a los tratantes y vaqueros, generaron la airada protesta de Antonio Bartolomé de Río y Malo y otros arrieros:

[...] dichas justicias han dado de todas las sacas en quitar con el pretexto de que es para el abasto de dicha ciudad de cada cien reses diez, las cuales nos obligan a que las dejemos con tanta perdida y daño nuestro que aun no nos pagan el costo que de ellas tenemos demás de darnos por perdidas algunas de ellas de que se sigue el perjuicio y vejación que se nos hace y nuevos costos de las personas que es fuerza que cuiden dicho ganado; y asimismo estando impuesto y ajustado que de todos los derechos paguemos de cada saca en cada un año sesenta pesos de oro corriente, se nos ha añadido un tomín más en cada peso que hacen sesenta, y siete de dicho oro con más un real en cada cabeza de ganado sin saber para que efecto es, solo por que pasa por dicha ciudad, siendo así que la costumbre ha sido sólo de los dichos sesenta pesos de oro corriente. (AGN, M 70, f. 60r.).

Cabe decir que los vecinos y la gente principal de Anserma tenían sus encomiendas y estancias en Vega de Supía, así como esclavos trabajando en los distritos mineros de Quiebralomo y Marmato. Muchos de esos negros habían sido comprados en Antioquia y en el valle de Aburrá. Gran parte de la carne que estos esclavos consumían provenía de las cercanas estancias que en Arma tenían los Jaramillo y los Velásquez de Obando. Otra fracción de las provisiones les llegaba de acarreto desde Buga, Cartago y $\mathrm{Cali}^{17}$. Ubicados en lugar estratégico, en frente de las partidas de los caminos de Popayán, Hervé y Moná,

\footnotetext{
${ }^{17}$ Según cuenta fray Jerónimo de Escobar, en su "Relación de Popayán" (1582), en Anserma "la riqueza de las minas es grande, hanse metido grandes quadrillas de negros y es de suerte que entre veynte y quatro vezinos abrá más de mil esclavos en las minas [...]. Es tierra falta de comidas llebase lo más de acarreto, la tierra es sana y de buen temple aquí están muy sobrellevados los pocos indios que han quedado por ser todos negros aunque andan algunos indios a las minas [...]. En este lugar son muchos los negocios que ay por las muchas mercaderías que a él acuden que cada día entran en él requas de mercaderías muy grandes porques mucho lo que aquí se consume entre negros y españoles [...]" (415-16).
} 
cerca de los principales centros agropecuarios de la Gobernación de Popayán (al sur) y no muy lejos de las sierras antioqueñas (al norte), en Anserma y su Vega de Supía, también residían intermediarios, quienes a cambio de una comisión monetaria hacían posible que se realizaran negocios entre algunos mineros antioqueños y los criadores payaneses. Mineros antioqueños como Fernando de Toro Zapata y Felipe de Herrera tenían intermediarios en Anserma, quienes les compraban ganado en Buga, Cartago y Roldanillo, con el que trataban de hacer frente a las crisis alimentarias, que en Antioquia eran frecuentes y en las que los precios del maíz y de los ganados subían de manera exorbitante.

En aquellos viajes, muchas veces superiores a los 800 kilómetros y en los que se arriaban miles de novillos por difíciles caminos llenos de atolladeros, resumideros, barrizales, tembladales y derrumbaderos, perfectamente podía fallecer una cuarta parte del ganado. Morían animales al vadearse los ríos; otros, por el cansancio; otros, por la fractura de una de las patas; otros se "enguacaban" o caían por precipicios, y otros morían por las fiebres producidas por el desgaste de los cascos (la despeadura) y el desolle de las canillas. Así, el viaje a pie para llegar al mercado o al matadero ocasionaba a las reses graves quebrantos. Por tal razón, los vaqueros hacían paradas en los lugares ricos en pastos, para evitar que las reses llegaran flacas a su destino, o las dejaban engordar en los ejidos de las villas y ciudades.

En esas largas travesías, unos treinta vaqueros debían encargarse del control de miles de animales. Debía llevarse un arria de por lo menos 60 mulas, las cuales cargaban a cuestas viandas y vituallas, especialmente sal, tasajo, maíz y plátano. Un grupo de equinos llevaba a los negros e indios vaqueros. Como los viajes duraban mucho, normalmente entre dos y tres meses, los vaqueros llevaban un excedente de mulas, otro de caballos y otro de los ganados; sobre todo de este último, dado que muchas reses morían por las circunstancias mencionadas o porque debían ser sacrificadas para el abasto de los mismos vaqueros. En los sitios, villas y ciudades por los que pasaban tales vaqueros, éstos debían tener amigos, conocidos o clientes, quienes resultaban útiles en las situaciones de apuro.

Cada hato, piara o arria tenía una vaca, una marrana o una yegua guía, usada como madrina, a la que la manada de animales seguía con sumisión. Tal animal era el más conocido por el vaquero y el más cuidado, pues se sabía que sin él el hato, la piara o el arria sería difícil de manejar. Era costumbre, heredada de las marismas andaluzas que ese animal llevara una campanilla al cuello. A pesar de los cuidados de los vaqueros, muchos animales se perdían, y cuando las 


\section{FRONTERAS}

de la historia

condiciones del terreno lo permitían (abundancia de aguas y sal), esos animales extraviados se volvían cimarrones. En otras ocasiones los ganados arriados retornaban a su querencia; es decir, al antiguo lugar donde se habían criado y cebado, lo que generaba graves inconvenientes a los vaqueros, dado que se retrasaba más la entrega de novillos o no se efectuaba; o peor aún, los animales aquerenciados atraían reses y novillos de otros dueños. Esto fue lo que le sucedió, hacia 1642, a un hato de 150 vacas de la mortuoria del cura Miguel de Heredia (dueño de la mejor propiedad ganadera del valle de Aburrá) enviados hacia Guarne, a la estancia del capitán Agustín de Burgos Antolínez. Esos ganados debían ser llevados por el camino que de "Rionegro va a Los Remedios" a siete leguas de la estancia del difunto cura, para evitar que retornaran a su antiguas dehesas; sin embargo, dichos animales se subieron por el camino de La Tasajera, a tan sólo una legua de distancia de su querencia, por lo que quedaron conociendo el camino de retorno a su antiguo hogar. Las reses llegaron a Guarne, y una vez allí, libres del ojo vigilante de los vaqueros, se escaparon de los corrales y regresaron a su antigua estancia en el valle de Aburrá, no sin llevar consigo a varios novillos que pertenecían a Burgos Antolinez. Por tal razón, la transacción no se efectuó y se comenzó un largo litigio entre dos grandes propietarios de ganado vacuno de la provincia de Antioquia (AHA, C 55, doc. 1477, f. 3r.).

A finales del siglo XVI, los ganados cimarrones llegaron a ser numerosos en el valle de Rionegro como resultado de centenares de novillos que, en 1573, se le fugaron a Rodrigo Hidalgo y Rangel, a Pedro Beltrán (suegro del anterior) y a Baltasar Alfaro, cuando conducían un hato de 500 reses hacia Los Remedios. Dichas reses se habían perdido cerca de la quebrada que hoy se denomina, y por tal suceso, Cimarronas (cerca al actual municipio de Marinilla). Aquellas vacas se reprodujeron considerablemente durante ocho años y la gente de los alrededores lo aperreaba y arcabuceaba a sus anchas. Indignado por tal situación, Rodrigo Hidalgo, en 1581, solicitó en merced, ante el cabildo de la ciudad de Arma, las tierras donde se albergaba este ganado asilvestrado, que para ese entonces pertenecía a la Gobernación de Popayán (AHA, $T$ 162, doc. 4246 , ff. $2 \mathrm{r} .-2 \mathrm{v}$.).

Al parecer, la merced se dio, pues para 1610 los hijos del solicitante (Jerónimo Hidalgo y Lorenza Hidalgo) le vendieron a Alonso Gómez una estancia de ganado mayor "que está en la Ceja términos de Arma". Por lo tanto, en la provincia de Antioquia, el cimarronaje de vacunos se dio entre las últimas dos décadas del siglo XVI y las cuatro primeras del XVII, aunque es posible que después se presentaran algunos casos excepcionales. En 1682, por ejemplo, en 
el hato y casas de Diego de Agudelo, ubicadas en el sitio de San Jerónimo, los avaluadores de sus bienes llegaron a contar 52 vacunos cimarrones, los que agrupados en atajos deambulaban por tales tierras. De vez en cuando acudían a los comederos y no se dejaban encerrar en el corral (AHA, $M$ 193, doc. 4769). Por su parte, llegó a haber cerdos cimarrones en el altiplano de Los Osos, ya muy entrado el siglo XVIII.

Por lo tanto, la provincia de Antioquia poseía una intrincada red de relaciones comerciales entre sus centros ganaderos y sus distritos mineros, lo que demuestra que desde finales del siglo XVI ya se había establecido un mercado pecuario con sus áreas de producción, de recolección y de consumo del producto. En sus núcleos pecuarios se practicaba la ganadería extensiva, en terrenos sumamente amplios, donde muchas veces la mano de obra resultaba insuficiente para vigilar los hatos y efectuar periódicamente rodeos; por otro lado, era usual que los linderos de las propiedades carecieran de talanqueras.

De modo que no sólo la actividad pecuaria le daba dinamismo a esta gobernación, sino que también la relacionaba con otras, la sacaba de su aislamiento geográfico y la alejaba completamente del antiguo ideal autárquico; en pocas palabras, le abría horizontes y perspectivas que transcendían su accidentada orografía. Asimismo, permitía que gentes de otras latitudes (bugueños, cartagueños, santafereños, tunjanos) circularan por sus caminos y se alojaran por temporadas en sus sitios, villas y ciudades. En fin, tan fuertes vínculos le abrían la posibilidad de tener contacto con una numerosa población desconocida, forastera y viandante.

La Antioquia del siglo XVII no era una sociedad cerrada, celosamente resguardada o ajena al devenir del mundo. No era una unidad independiente y extraña a sus vecinos. Por el contrario, tenía estrechos vínculos comerciales con Quito, Riobamba, Ibarra, Pasto, Popayán, Neiva, Nóvita, Citará, Mariquita, Santafé, Cali, Buga, Cartago, Roldanillo, Anserma, Los Remedios, Mompox, Tamalameque, Cartagena y Santa Marta. Las relaciones con unas y otras eran disímiles: directas o indirectas, intensas o frágiles. Desde allá le llegaban, fuera de mercaderías, vituallas y ganado menor y mayor en pie, todo un cúmulo de noticias, ideas y nociones acerca de otros individuos que integraban un territorio vasto, multifacético y diverso denominado Nuevo Reino de Granada.

En síntesis, con este artículo se pretendió demostrar, con base en fuentes primarias provenientes de diversos archivos del país, que no sólo la minería era importante en la provincia de Antioquia, sino que también era relevante la 


\section{FRONTERAS}

de la historia

Vol.12 / 2007

actividad pecuaria, a pesar del reducido tamaño de los hatos si se comparan con los de otras gobernaciones neogranadinas, pues fue la base de un intrincado mercado provincial e interprovincial con sus respectivas áreas de producción, recolección, distribución y consumo. A la par, fue un elemento vital en la cultura material de dicho espacio y, como si fuera poco, resultó ser una actividad más estable que la minería misma, en la que muchos de sus habitantes invirtieron su sudor y esfuerzos. Así que también incidió en el surgimiento de negocios y fortunas personales y familiares que se derivaron de la oferta de carne, sebo, ganado mayor, ganado menor y animales de labor en los epicentros auríferos.

\section{Bibliografía}

\section{Fuentes primarias}

Archivo Arzobispal de Popayán, Popayán, Colombia. Fotogramas del Archivo General de la Nación, Bogotá, Colombia (AAP).

Archivo Central del Cauca, Popayán, Colombia (ACC)

Notaría Primera $(N P) 13$.

Archivo Histórico de Antioquia, Medellín, Colombia (AHA).

Capellanías (C) 55 .

Mortuorias (M) 162, 193, 196, 197, 206, 215, 223, 224, 229, 274, 281, 291, 293, 307, 308, 311, 320, 321, 323.

Tierras (T) 141, 155, 158, 160, 162, 173, 185.

Archivo Histórico de Cartago, Cartago, Colombia (AHC).

Sección Judicial ( $J) 1$.

Archivo Histórico de Medellín, Medellín, Colombia (AHM).

Archivo Histórico Judicial de Medellín, Colombia (AHJM).

Archivo General de la Nación, Bogotá, Colombia (AGN), Sección Colonia. 
Contrabandos $(C) 17$.

Impuestos Varios (IV) 19.

Juicios Civiles de Antioquia (JCA) 13.

Juicios Criminales (JC) 18.

Miscelánea $(M)$ 37, 62, 70.

Testamentarias de Antioquia (TEA) 17.

Tierras de Antioquia (TA) 1, 4.

Notaría Única del Circuito de Santa Fe de Antioquia, Santa Fe de Antioquia, Colombia (NUSA).

Libro de los años 1635-1640(L).

\section{Fuentes secundarias}

Arboleda, Gustavo. Historia de Cali. Cali: Universidad del Valle, 1956.

Castaño Pareja, Yoer Javier. "Comercio ganadero en el occidente colombiano, siglos XVI y XVII". Ponencia. XII Congreso de Historia de Colombia. Popayán, 4 al 8 de agosto de 2003.

Colmenares, Germán. Cali: terratenientes, mineros y comerciantes. Bogotá: Tercer Mundo, 1997.

—. Popayán, una sociedad esclavista (1680-1800). Bogotá: Tercer Mundo, 1997.

Escobar, fray Jerónimo de. "Relación de Popayán". Relaciones y visitas a los Andes. S. XVI., ed. Hermes Tovar Pinzón. Bogotá: Colcultura; Instituto de Cultura Hispánica, 1993.

Gamboa, Jorge Augusto. "La dote matrimonial a finales del siglo XVI: El caso de la provincia de Pamplona en el Nuevo Reino de Granada (15741630)". Anuario Colombiano de Historia Social y de la Cultura 24 (1997). 


\section{FRONTERAS}

de la historia

Vol.12 / 2007

Herrera, Alonso de. Libro de agricultura de Alonso de Herrera, que trata de la labrança de los campos y muchas particularidades y provechos suyos. Pamplona, España: Consejo Real de Navarra, 1605.

Jaramillo, Roberto Luis. "De pueblo de Aburraes a villa de Medellín". Historia de Medellín. T. 1. Medellín: Compañía Suramericana de Seguros, 1996. 106-19.

Molina Londoño, Luis Fernando. La avicultura en Colombia. Bogotá: Fenavi; Fonav, 2002.

Ortiz Aristizábal, Santiago. "La minería de la sal en Antioquia". Trabajo de grado de licenciatura. Universidad de Antioquia, Medellín, 1989.

Patiño, Víctor Manuel. Historia de la actividad agropecuaria en América Equinoccial. Cali: Imprenta Departamental, 1965.

Roulin, François Desire. "Memoria sobre las alteraciones que se descubren en los animales domésticos que se condujeron del Antiguo al Nuevo Continente, por el doctor Roulin". Viajes científicos a los Andes ecuatoriales, Jean Baptiste Boussingault y François Desire Roulin. París, 1849. Edición facsímilar. Bogotá: Instituto Colombiano de Cultura Hispánica, 1991. 225-43.

Vásquez de Espinosa, Antonio. Compendio y descripción de las Indias Occidentales. Washington, 1948.

Fecha de recepción: 5 de marzo de 2007.

Fecha de aprobación: 30 de julio de 2007 . 